\title{
Neck Bypass Modification for Inferior Trapezius Flaps: A Discussion of Surgical Technique and Experience
}

\author{
Armando M. Chiong, Jr., Olivia Agnes D. Mejia, Alzhes R. Buelva and Katrina Anne R. Balmores \\ Department of Otorhinolaryngology, College of Medicine and Philippine General Hospital, University of the Philippines Manila
}

\begin{abstract}
The inferior trapezius flap (ITF) is useful as a primary means of head and neck reconstruction or as a salvage flap when a previous flap has failed. This report illustrates a neck bypass modification technique which places the pedicle external and lateral to the neck, thereby 1 ) increasing the flap's reach and 2) decreasing compression from subcutaneous tunneling. It also describes the authors' experience with this technique.
\end{abstract}

Key Words: trapezius flap, lower island trapezius flap, inferior trapezius flap, head and neck reconstruction

\section{Introduction}

The trapezius flap (TF) is a versatile flap in head and neck reconstruction. ${ }^{1}$ It is a myocutaneous pedicled flap comprised of thin, supple tissue that provides a long arc of rotation necessary to reach distal head and neck defects. ${ }^{2}$ Each region of the trapezius (superior, middle, or inferior) may be used for reconstruction depending on the location and distance of the defect to be covered. The inferior trapezius flap (ITF), which is also known as the lower, vertical, or extended island trapezius flap, is the most versatile and is considered dispensable, causing minimal disability post-operatively. ${ }^{1}$ Though less commonly used than the pectoralis major myocutaneous flap (PMMF), the TF can serve as a "workhorse" for head and neck reconstruction, particularly in areas not easily reached by the PMMF, such as the scalp and occiput.,4

Nowadays free flap reconstruction has been described as the preferred method of head and neck reconstruction, but certain patient populations do not make good candidates for such surgery like those with peripheral arterial atherosclerotic disease or chemoradiation prior to surgery. ${ }^{1,5}$ A regional pedicled flap such as a TF may prove to be the

Presented at the 16th ASEAN ORL-HNS Congress, November 11-13, 2015, Chiang-Mai, Thailand.

Corresponding author: Olivia Agnes D. Mejia, MD

Department of Otorhinolaryngology

2nd Floor, Ward 10

Philippine General Hospital

University of the Philippines Manila

Taft Avenue, Ermita, Manila 1000 Philippines

Telephone: +6325548400 local 2151 or 2152

Email: oliviamejiamd@yahoo.com better first choice for soft tissue reconstruction in such cases because it provides a more constant and reliable blood supply which significantly contributes to flap survival. The TF can also be utilized as salvage flap for post-irradiation recurrences or failed flap reconstruction. ${ }^{6,7}$

This report highlights the authors' surgical technique in harvesting ITF and illustrates the neck bypass modification that 1) further maximizes the reach of the ITF and 2) eliminates the compression created by subcutaneous tunneling while positioning the vascular pedicle external and lateral to the neck.

\section{Methods}

From 2005 to 2013, four patients underwent ITF reconstruction with the neck bypass modification. All had large face and scalp defects resulting from either tumor excision or osteoradionecrosis from post-operative radiation therapy.

In harvesting the ITF, the size of the defect was first measured in centimeters. The acromioclavicular joint, the spinous process of C7 and the T12 vertebra were identified as landmarks. A line connecting all three points estimated the location and borders of the trapezius muscle. The borders of the scapula were marked. In estimating the size of the flap, approximately $2 \mathrm{cms}$ were added to the measured size of the defect in all directions in order to compensate for the expected flap contraction post-operatively.

The descending branch of the transverse cervical artery was the vascular supply used in developing the pedicle. Its anatomic location was based on a local study done by Gallardo et. al on 18 Filipino cadavers. The results of this study showed that the transverse cervical artery was located at the junction between the medial three-fifths and lateral two-fifths of the line drawn from the C7 vertebra to the acromioclavicular joint. The descending branch of the transverse cervical artery, which was identified as the dominant blood supply to the inferior trapezius, was noted to lie within the area of the line drawn inferior and perpendicular to this junction. ${ }^{8}$ (Figure 1).

The flap was drawn medial and inferior to the medial border of the scapula with the markings for the blood supply coinciding with the flap. Marking for a "tail' incision was made, which extended inferior and perpendicular from the most caudal portion of the island flap. The initial skin incision was made along the inferior portion of the island flap 


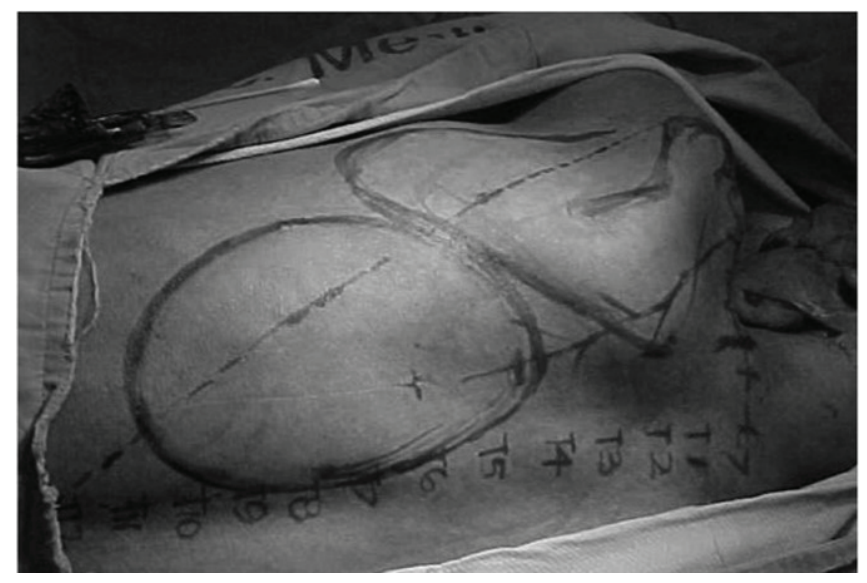

Figure 1. Landmarks for ITF: trapezius outlined using $C 7$, T12, and acromion as landmark. Descending branch of transverse cervical artery drawn.

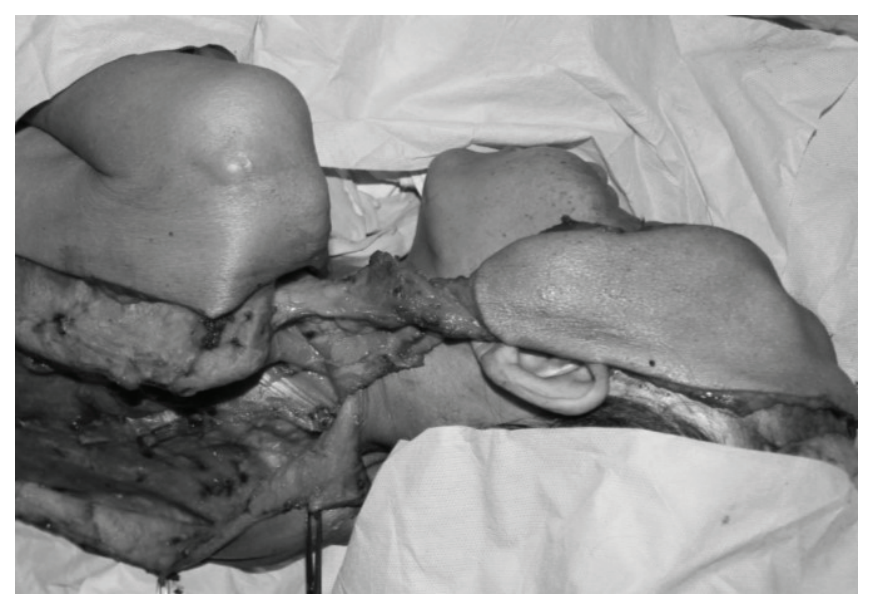

Figure 2. Neck Bypass Modification. Positioning the pedicle lateral and external to the neck.

which allowed visualization of the trapezius in relation to the overlying skin. The tail incision provided easier identification of the trapezius in relation to the latissimus dorsi. Once the trapezius muscle was identified beneath the skin of the island flap, completion of the incisions was made. The flap was separated from the underlying rhomboid muscles. The descending branch of the transverse cervical artery was identified. The muscle fibers were then transected superiorly following the course of the artery, thereby creating the vascular pedicle. Because of very large defects located on the scalp, face, and forehead, dissection of the pedicle was up to the base of the neck at the level of C7. The rhomboids and levator scapulae were not violated. To further increase the reach of the flap, the neck bypass modification was used wherein the pedicle was placed external and lateral to the neck instead of tunneling it subcutaneously. This technique increased the reach by approximately $4 \mathrm{~cm}$. It also decreased the risk of pedicle compression from subcutaneous tunneling (Figure 2, Figure 3).

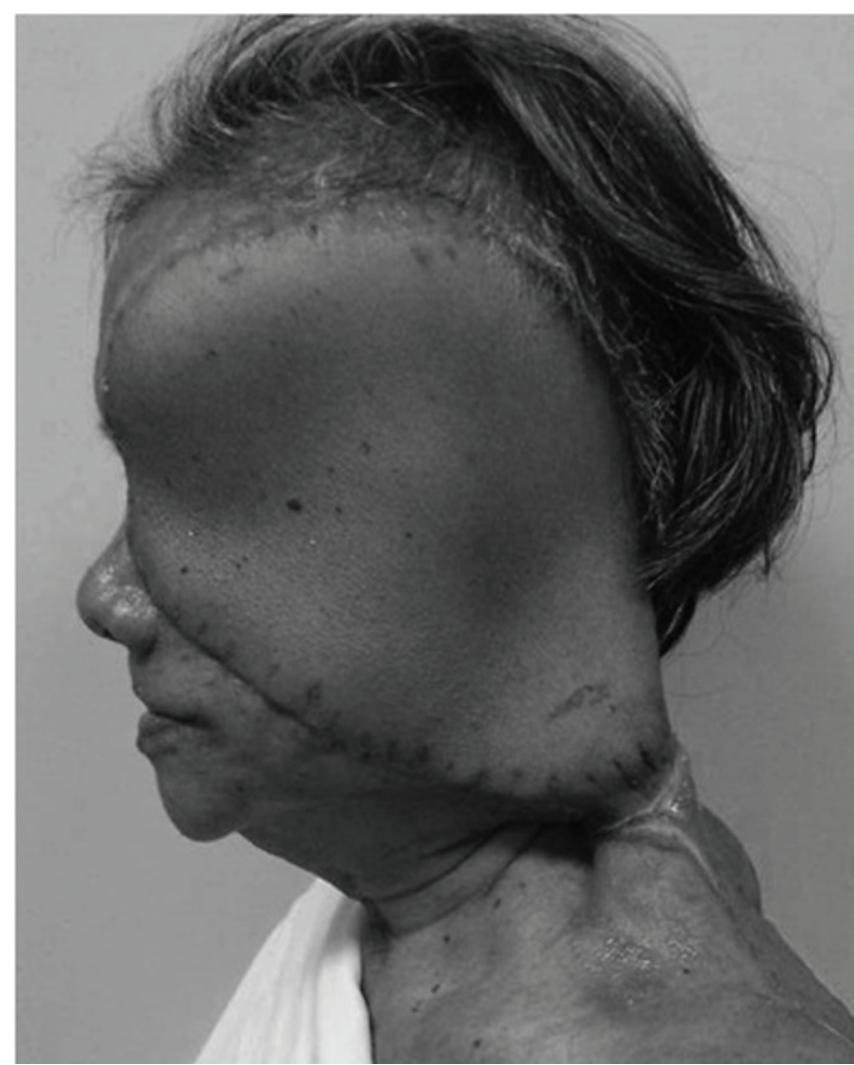

Figure 3. Neck Bypass Modification. Flap prior to amputation.

\section{Results}

Table 1 illustrates the relevant details of the patients who underwent the neck bypass modification for ITF reconstruction. All flaps provided coverage for the defect. In all cases, the descending branch of the transverse cervical artery was the blood supply identified and used in developing the vascular pedicle. The complications encountered ranged from Grade I to Grade IIIb based on the Calvien-Dindo classification of surgical complications. ${ }^{9}$ These included partial flap necrosis and recipient site infection in one, which was debrided and resutured under general anesthesia, minor flap dehiscence and donor site seroma in another, which was managed conservatively, and donor site infection in one patient, which was treated with IV antibiotics and bedside debridement. The donor sites were either closed primarily, left to granulate, or grafted with a split-thickness skin graft. In all cases, the pedicle was cleaned daily with chlorhexidine acetate BP dressing (Bactigras $^{\mathrm{TM}}$ Smith and Nephew, Canada) and wet to dry gauze dressing. All vascular pedicles were ligated approximately 2 months after initial reconstruction and among the flaps that survived, none of them developed further complications post-amputation. Shoulder function was preserved in all patients. Pain was adequately controlled by medication and initial post-operative pain markedly improved within 1-2 weeks as subjectively reported by the patients. 
Neck Bypass Modification for Inferior Trapezius Flaps

Table 1. Outcomes of Neck Bypass Modification

\begin{tabular}{|c|c|c|c|c|c|c|}
\hline $\begin{array}{l}\text { Patient } \\
\text { No. }\end{array}$ & $\begin{array}{c}\text { Age/ } \\
\text { Gender }\end{array}$ & Diagnosis & Area of Defect & $\begin{array}{c}\text { Size of } \\
\text { Defect }(\mathrm{cm})\end{array}$ & $\begin{array}{l}\text { Size of Flap } \\
(\mathrm{cm})\end{array}$ & Complication \\
\hline 1 & $21 / \mathrm{M}$ & $\begin{array}{l}\text { Sinonasal Giant Cell Tumor, Left s/p } \\
\text { excision and radiotherapy (2005-2006) }\end{array}$ & Forehead and scalp & $15 \times 12$ & $19 \times 14$ & none \\
\hline 2 & $56 / \mathrm{F}$ & $\begin{array}{l}\text { Osteoradio-necrosis, forehead } \\
\text { secondary to recurrent adenoid cystic } \\
\text { carcinoma s/p excision and } \\
\text { radiotherapy (2011-2012) }\end{array}$ & Forehead & $22 \times 8.5$ & $26.5 \times 10$ & $\begin{array}{l}\text { Flap dehiscence at most distal } \\
\text { portion, approximately } 1.0 \times 0.75 \mathrm{~cm} \\
\text { Seroma formation at donor site }\end{array}$ \\
\hline 3 & $64 / F$ & $\begin{array}{l}\text { Squamous Cell Carcinoma, Left Fronto- } \\
\text { temporal region (2013) }\end{array}$ & Fronto-temporal region, left & $19 \times 15$ & $23 \times 17$ & Surgical site infection at donor site \\
\hline 4 & $54 / \mathrm{M}$ & $\begin{array}{l}\text { Soft tissue sarcoma, scalp, recurrence } \\
(2013)\end{array}$ & Left antero-superiorcalp & $15 \times 13$ & $18 \times 15$ & $\begin{array}{l}\text { Partial flap necrosis, surgical site } \\
\text { infection at recipient site }\end{array}$ \\
\hline
\end{tabular}

\section{Discussion}

TF reconstruction is an indispensable technique for head and neck reconstruction even in the era of free flap surgery. Maximizing the flap's arc of rotation and reach is necessary to ensure coverage of the defect without tension. Techniques in designing and harvesting the ITF vary slightly and the core principles are the same. In general, the landmarks used are the muscle borders, medial border of the scapula, and thoracic spine up to T12 vertebrae. Marking of the landmarks and drawing of the planned island flap may be done while the patient is sitting ${ }^{10}$ or on lateral decubitus position. ${ }^{1}$

The differences in harvesting ITF largely depend on the surgeon's personal technique. Squaquara et. al describe their method as making the initial incision from the base of the neck to the superior-most border of the planned island flap. The island flap is incised circumferentially and lifted laterally to medially once the trapezius muscle has been identified on all borders. ${ }^{10}$ In the technique presented in this report, the initial incision is instead made at the most inferior portion of the island flap. The deemed advantage of this is that by incising at the inferior portion, a possible random flap can be identified early on. This can occur if the flap is too large, too inferiorly located, or if the trapezius muscle is small, which can occur as an anatomic variant. It provides the surgeon with a leeway for possible adjustment if a random flap is deemed too large.

Another difference in technique is the placement of the pedicle. In 2011, Nasser et. al developed the racquet-shaped modification in designing island pedicled flaps to reduce complications brought about by pedicle compression secondary to subcutaneous tunneling. In his technique, the entire pedicle is covered by a strip of skin. An incision on the skin of the neck is made from the defect to the pivot point of the pedicle. The flap is then transposed to the defect and the pedicle, with its overlying skin, is fitted into the skin incision on the neck. ${ }^{11}$ In the neck bypass modification, the same problem is addressed however no additional neck incisions are made. By placing the pedicle external to the neck, the compression created by subcutaneous tunneling is avoided.

Perhaps the more important advantage of the neck bypass modification is the increase in reach that it provides.
The cases presented in this report were of particularly large and distal soft tissue defects involving the superior scalp, face, and forehead (Table 1). By bypassing the length of the neck, this modification increases flap reach by as much as 4 $\mathrm{cm}$ - a significant length that may be crucial in covering large defects.

Disadvantages of this method include the need for a second-stage pedicle amputation and meticulous cleaning and dressing. Preliminary results shown in this report are promising but more cases using the neck bypass modification are required in order to test the reliability of this technique and assess its pitfalls. The maximum size of the island flap and its distance from the pedicle remain to be determined. Lastly, the shortest and safest time for pedicle amputation should be investigated to minimize patient postsurgical care.

\section{Acknowledgments}

The authors would like to acknowledge the following: Dr. Charlotte M. Chiong for comments on the manuscript, and Dr. Cesar Vincent L. Villafuerte III for lending his surgical expertise in the cases described.

\section{References}

1. Yoon SK, Song SH, Kang N, Yoon YH, Koo BS, Oh SH. Reconstruction of the head and neck region using lower trapezius musculocutaneous flaps. Arch Plast Surg. 2012; 39(6):626-30

2. Urken ML, Naidu RK, Lawson W, Biller HF. The lower trapezius island musculocutaenous flap revisited: Report of 45 cases and a unifying concept of the vascular supply. Arch Otolaryngol Head Neck Surg. 1991; 117(5):502-11.

3. Attia AA. The lower trapezius myocutaneous flap for reconstruction after surgery for head and neck cancer: NCI Experience. J Egypt Natl Canc Inst. 2002; 14(3):185-91

4. Elshafiey MM, Mebed AH, Abd Elmaksoud AE, Attia AA. Continuous validity of pedicled myocutaneous and myofascial flaps in reconstruction after surgery for head and neck cancer. J Egypt Natl Canc Inst. 2009; 21(3):249-63.

5. Shah JP, Patel SG, Singh B. Reconstructive Surgery. In: J Shah JP, Patel SG, Singh B. Jatin Shah's Head and Neck Surgery and Oncology, $4^{\text {th }}$ ed. Elsevier, 2012. pp. 712-751.

6. Uğurlu K, Ozçelik D, Hüthüt I, Yildiz K, Kilinç L, Baş L. Extended vertical trapezius myocutaneous flap in head and neck reconstruction as a salvage procedure. Plast Reconstr Surg. 2004; 114(2):339-50. 
7. Chen WL, Li J, Yang Z, Huang Z, Wang J, Zhang B. Extended vertical lower trapezius island myocutaneous flap in reconstruction of oral and maxillofacial defects after salvage surgery for recurrent oral carcinoma. J Oral Maxillofac Surg. 2007; 65(2):205-11.

8. Gallardo JM, Alarva III VD, Chiong Jr AM. The Extended Island Trapezius Myocutaneous Flap: Localization of the Vascular Pedicle. Philippine Journal of Otorhinolaryngology \& Head and Neck Surgery. Jan-Mar 1999. Vol 14 No 1. 8-14.
9. Dindo D, Demartines N, Clavien PA. Classification of surgical complications: a new proposal with evaluation in a cohort of 6336 patients and results of a survey. Ann Surg. 2004; 240(2):205-13.

10. Squaquara R, Kim Evans KF, Spanio di Spilimbergo S, Mardini S. Intraoral reconstruction using local and regional flaps. Semin Plast Surg. 2010; 24(2):198-211.

11. Nasser S, Allah YA, Shaker AA. Racquet-shaped modification of the island pedicle flaps: a simple design to increase its versatility and to decrease the complication rate. Egypt, J Plast Reconstr Surg. 2011; 35(1):13-40.

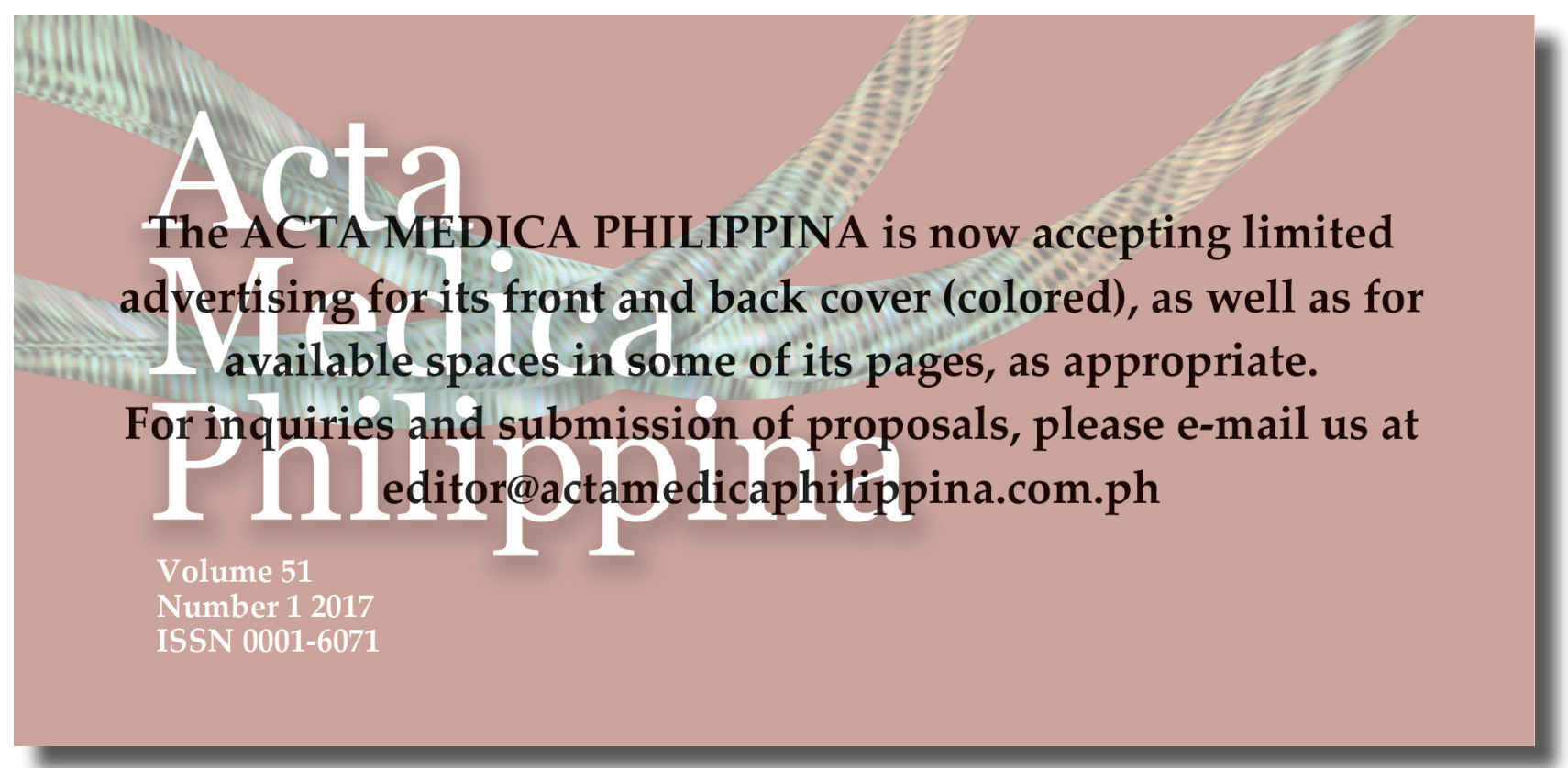

